\title{
Improving lung cancer outcomes through smoking cessation: the Women Against Lung Cancer in Europe (WALCE) experience
}

\author{
Enrica Capelletto ${ }^{1}$, Francesco Passiglia ${ }^{1}$, Federica Ferraresi ${ }^{2}$, Stefania Vallone $^{2}$, Silvia Novello $^{1}$ \\ ${ }^{1}$ Department of Oncology, University of Turin, AOU San Luigi Gonzaga, Orbassano, Torino, Italy; ${ }^{2}$ Women Against Lung Cancer in Europe Onlus, \\ Orbassano, Turin, Italy \\ Contributions: (I) Conception and design: All authors; (II) Administrative support: None; (III) Provision of study materials or patients: None; (IV) \\ Collection and assembly of data: None; (V) Data analysis and interpretation: None; (VI) Manuscript writing: All authors; (VII) Final approval of \\ manuscript: All authors. \\ Correspondence to: Silvia Novello, MD, PhD. Department of Oncology, University of Turin, AOU San Luigi Gonzaga, Orbassano, Torino, Italy. \\ Email: silvia.novello@unito.it.
}

\begin{abstract}
Being lung cancer the main cause of cancer-related mortality worldwide, mainly dependent on tobacco consumption, fighting the tobacco epidemic and concretely acting in terms of prevention represents a current urgent need. Indeed, it has become clear that the significant reduction in tobacco consumption would result in the prevention of a large fraction of lung cancer cases and other smoking-related diseases. Women Against Lung Cancer in Europe (WALCE) is a non-profit European organisation with more than 10 years of experience, whose mission is promoting communication strategies and awareness initiatives, customized on recipients age, to aware public opinion and decision makers on damages of smoking on health and spreading accurate and updated information in order to support people affected by lung cancer and their caregivers. In this review we will provide a summary of WALCE commitment and experience in the field of smoking cessation and lung cancer prevention.
\end{abstract}

Keywords: Women Against Lung Cancer in Europe (WALCE); advocacy; smoking; lung cancer; prevention

Submitted Jan 20, 2020. Accepted for publication Mar 12, 2020.

doi: $10.21037 /$ jtd.2020.03.76

View this article at: http://dx.doi.org/10.21037/jtd.2020.03.76

\section{Introduction}

Updated epidemiological data on the United States (US) population have recently described a continuous reduction trend of lung cancer incidence, even if it still remains the main cause of cancer mortality, estimating 72,500 new deaths in men and 63,220 in women for the $2020(23 \%$ and $22 \%$ of all cancer deaths, respectively) (1). Similarly, in Europe lung cancer has the highest incidence rates in both sexes: female incidence has constantly risen up, overtaking breast cancer around 2016, while in 2019 female lung cancer deaths have exceeded breast cancer ones $(96,800$ versus 92,800$)(2)$. According to the World Health Organization (WHO) report, cancer is the second leading cause of death globally, and lung cancer has been responsible for an estimated 1.76 million deaths in 2018 (3).
Particularly, in Italy we have recently witnessed a small and steady decrease of lung cancer incidence and mortality in men $(-1.6 \% /$ year; $-1.9 \% /$ year $)$, along with a significant increase among women $(+2.2 \% /$ year; $+0.7 \% /$ year $)(4)$. The patterns of lung cancer incidence worldwide are mainly dependent on tobacco consumption, being smoking habit cause by itself for over $80 \%$ of all lung cancer cases, with exposure to air pollution, radon, or chemicals, as well as a family history of lung cancer, likely accounting for the majority of the remaining cases (5).

Improving survival outcomes for the wide population of lung cancer patients means not only a deepener knowledge of disease biology leading the development of new treatment strategies, but also fighting the tobacco epidemic worldwide and concretely acting in terms of prevention. 
The International Association for the Study of Lung Cancer (IASLC), along with many other scientific societies involved in this field, recognized that the solution to the tobacco problem lies in the primary prevention of tobacco initiation. The IASLC launched in 2019 a program called Lung Ambition Alliance with the ambitious goal to double 5 -year lung cancer survival by 2025 with different actions worldwide (https://www.lungambitionalliance.com). Indeed, it has become clear that the both cancer- and not cancerrelated mortality throughout adulthood smokers is $2-3$ times the mortality observed in never-smokers, meaning an average 10-20 years reduction of the overall life-expectancy (6). Another important goal to be pursued is the cessation of smoking attitude by individuals addicted to nicotine, since it has been largely demonstrated that stopping smoking works, leading to a significant gain of life expectancy of about 10, 9, and 6 years for people who have stopped at 30,40 , or 50 years of age, respectively (7).

The 2013 World Health Assembly called on governments to adopt legislative measures aiming to reduce the smoking prevalence by about 30\% within the year 2025 (8). The WHO Framework Convention on Tobacco Control recommended additional interventions, such as the WHO six-points MPOWER initiative, to further reduce tobacco consumption across different countries (9).

The rigorous adoption of several measures by European Governments, including limitations to whom and where tobacco can be sold, smoking ban in public places, cigarette price increase, shocking images on packages cover showing the dangerous effects of smoking, produced to an immediate drop out in cigarette consumption. However, additional efforts are needed by governments, scientific societies, health professionals, advocacy groups, journalists, and other opinion leaders, in order to aware public opinion and decision makers on smoking-related damages, since it became clear that a significant reduction in tobacco consumption would result in the prevention of a large fraction of lung cancers. In this review we will provide a summary of Women Against Lung Cancer in Europe (WALCE) commitment and experience in the field of smoking cessation and lung cancer prevention.

\section{WALCE mission}

WALCE is a non-profit European organisation born in 2006 with the primary aim to increase women's awareness about lung cancer in female population and to support patients and relatives during the difficult path of disease, focusing the attention also on the leading role of women as caregivers (10). Since the first years of activity, WALCE has been involved in multiple research projects concerning the better definition of gender differences in lung cancer and in primary prevention projects, trough educational materials and communication tools specifically designed and produced by the Association. WALCE also provides updated news about lung cancer, in terms of risk factors, early diagnosis, treatment modalities and related side effects, offering to patients and relatives the possibility to be adequately supported during the cancer care program, through an active involvement in multiple educational activities.

\section{WALCE primary prevention campaigns}

According to its mission, WALCE aims to promote communication strategies to aware public opinion and decision makers on damages of smoking on health. WALCE is coordinating different awareness initiatives, customized on recipients age. The idea to create prevention campaigns about tobacco damage on health on the basis of the different characteristics of the target population (age, sex, peculiar period of life, such as pregnancy), as well as the adopted communication channel for the campaign, is the real strength of the Association and, probably, the reason of the success achieved across the last years.

\section{Children campaign}

Aimed at 9-11-year-old pupils, "I'm not smoking that" (Figure 1) is a primary prevention campaign on smoking side effects on health endorsed by the National Institute of Health, offered by WALCE (for free) to Italian primary schools. After conducting a pilot experience, this primary prevention campaign started in 2011, immediately achieving great success. It is based on simple stories of everyday life, told by the protagonist children, characters in which pupils can easily identify themselves in order to tackle, with gradualness and lightness, important topics concerning health. Through an educational kit (composed by entertaining and illustrative contents specifically designed for children) in classrooms, teachers may promote positive attitudes aiming at healthy lifestyle and deviating from the smoking habit. WALCE also facilitates the intervention of a pulmonologist, when request by teachers who are able to 


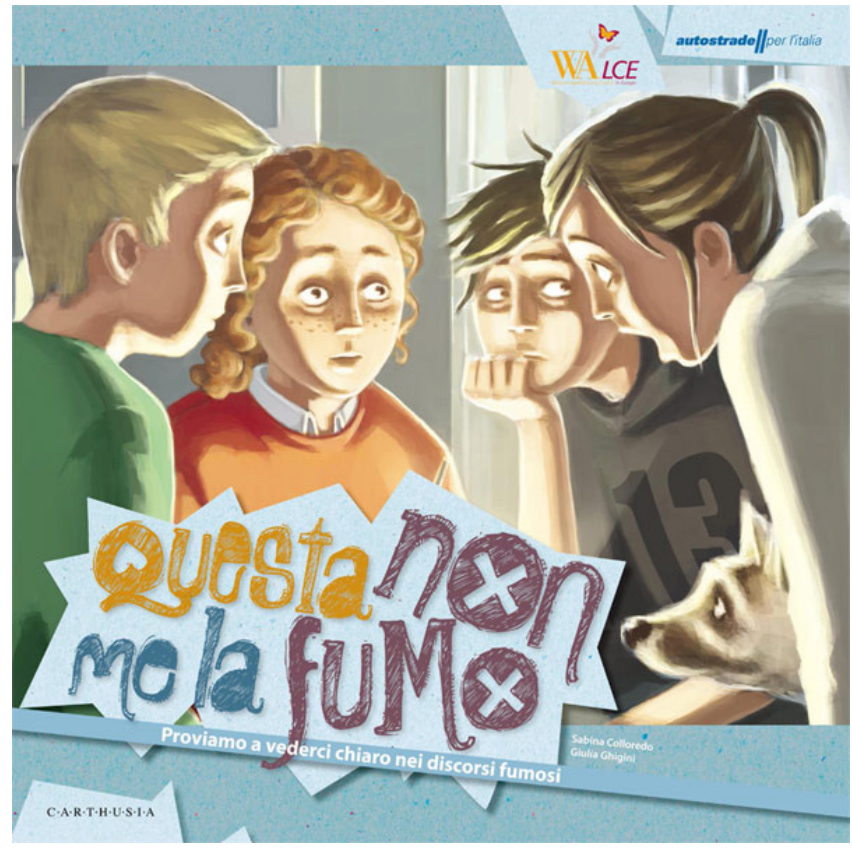

Figure 1 "I'm not smoking that", the WALCE's primary prevention campaign designed for children (photo: original source, property of WALCE). WALCE, women against lung cancer in Europe.

interactively illustrate the scientific aspects related to the innumerable smoking associated damages.

To date, over 24,000 pupils and 1,010 student classes have already joined the campaign. This material is available in Italian, French and English language.

\section{Teens campaign}

The book entitled "Ash of stars - Cinema, smoking habit and adolescents" focuses great attention on adolescence, pointing out the link between smoke scenes in recent movies and this habit in general population, especially in teens. European countries do not have any kind of legislation concerning the regulation of movies containing this type of scenes: WALCE aims to introduce stricter rules to limit the possibility of young people to access film containing unjustified smoking scenes and to avoid that movies become an instrument for tobacco advertising. Basing on cinematography, this book is a useful tool for teachers to stimulate discussion among students about smoking prevention and awareness programs.

The idea to design a prevention campaign dedicated only to teens rose from epidemiological data showing as the first cigarette is lit usually before the age of 18 (11); in Italy 18.1 years, 17.6 for boys, 18.8 for girls (12). In the past few years, we are witnessing an increasing attitude to smoke among Italian teenagers, with $11 \%$ of "baby smokers" reported in 2018, representing one of the highest percentages in Europe. Teens are the most vulnerable part of society, but also those most exposed to smoking damages, since they are still growing, easily driven by emulation and influenced in their habits by unsuitable educational models.

The step succeeding "Ash of stars" has been "Blaam", a digital project using an app as a tool, where people can point out smoke scenes in movie or TV series. The purpose of this project is to increase the awareness about the negative effects that smoking can produce (especially on teens) in movie scenes. The ambition is to attract the attention of the world of cinema on this topic and make it able to expose simple warnings before any movies.

\section{Communication tools and initiatives for adult population}

WALCE has also created a motivational web-based video, easy to use and extremely informative for the young-adult population illustrating smoking damage and the potential advantages derivated from quitting (13). This tool has been realized with the participation of exceptional testimonials (top-models, actors and sportsmen extremely popular in Italy and whose image was easily reconnected to a healthy lifestyle), and its capillarization still remains fundamental for the good performance of the same.

WALCE pursues the primary prevention aim through a campaign "in the field" named "Go out of the Tunnel. Don't burn away your future", a smoking prevention program addressed to general public, media and political institutions. This campaign consists on a structure shaped as a giant cigarette committing pulmonologists and oncologists to perform counseling, display educational materials on smoking cessation and provide a basic spirometry test to people attending. In Italy "Go out of the Tunnel" has been organized as a roadshow and, between 2015 and 2018, it has toured nine major Italian cities (Figure 2). Over 15,000 people visited the Tunnel, involving groups of heterogeneous age (young people, adults and elderly) with more than 3,500 spirometries performed. The program has been endorsed by the Italian Parliament, and during the past years many celebrities and politicians have attended the Tunnel in order to sensitize media and political institutions to the tobacco problem.

At European level, during the World No-Tobacco Day 


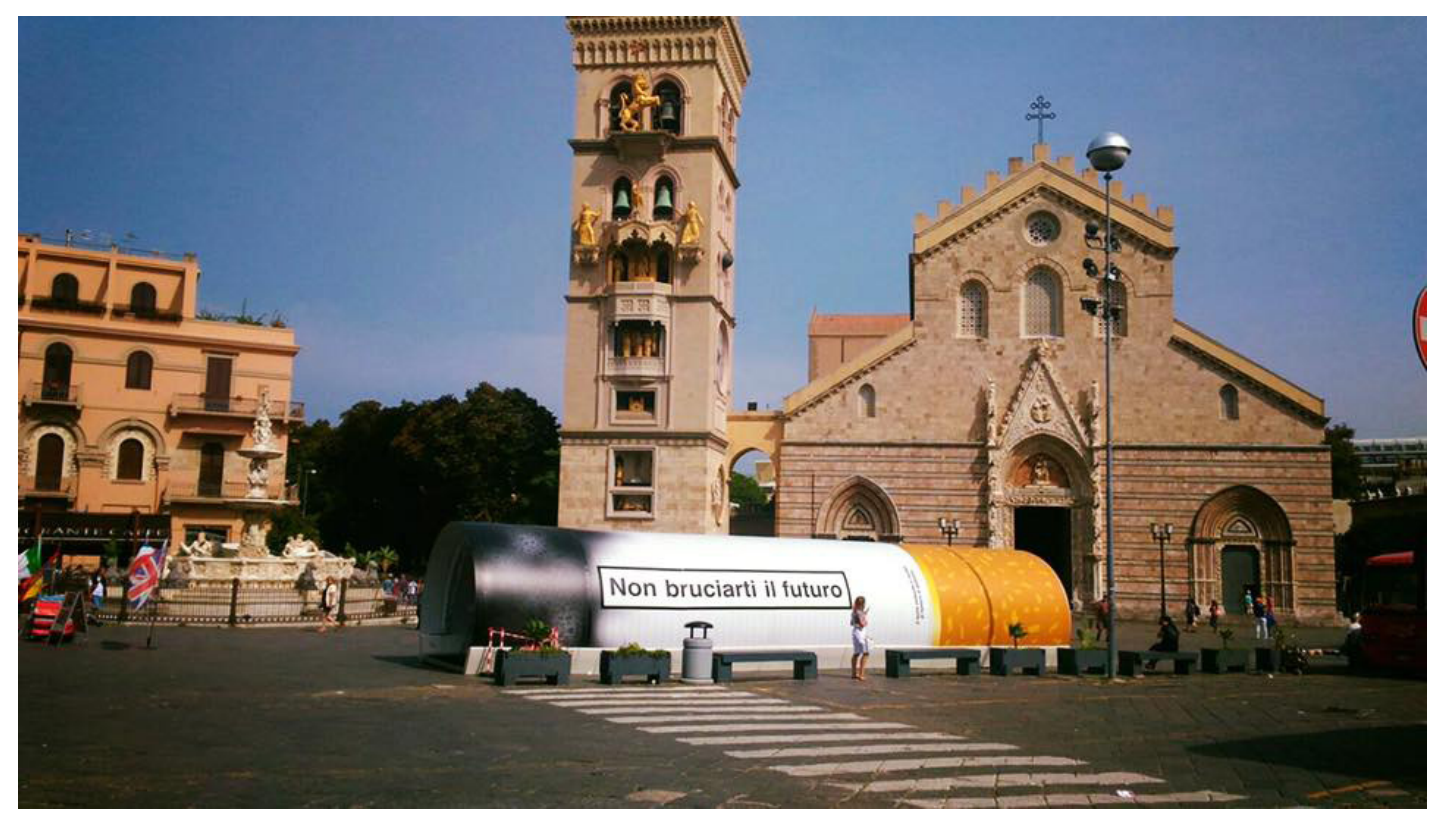

Figure 2 "Go out of the Tunnel. Don't burn away your future", the prevention campaign offered by WALCE to general public, media and political institutions (photo: original source, property of WALCE). WALCE, women against lung cancer in Europe.

2017, a 2-day Tunnel exhibition took place in Brussels. As result, 450 spirometry have been performed and 600 people of any age, mainly smokers, joined the Tunnel asking information regarding smoke-related diseases and smoking cessation programs.

In 2019 WALCE, in cooperation with two major Spanish organizations, "Fundación MÁS QUE IDEAS" and "AEACaP-Asociación Española del Cáncer de Pulmón”, and endorsed by the IASLC, The Lung Ambition Alliance and "Fondazione Insieme contro il Cancro", promoted a "Go out of the Tunnel" event focused on primary prevention and awareness on lung cancer, during the 20th World Conference on Lung Cancer-WCLC 2019, that took place in Barcelona, Spain. During this 2-day exhibition, 400 people visited the tunnel and 124 spirometries have been performed.

\section{Pregnant women}

In order to complete the needs overview, in November 2017 WALCE organised a smoking cessation campaign addressed to pregnant women, entitled "Hope it's the last one"; the program was accompanied by a funny toy designed for the newborn child: "Ector the Protector Bear", a teddy bear able to coughs if exposed to smoke. In parallel, a counseling service was also offered by gynecologists and pulmonologists, to promote healthy lifestyles.

\section{Other relevant activities}

\section{Website}

In the era of communication, digital reality is characterized by a fast stream of knowledge and a wide complexity of web-based articles which overtake the conventional communication modalities (newspapers, radio, television and often also scientific communications); in this context, for non-professionals, the possibility to discern between real and fake news is a right that must be protected.

The WALCE website is one of the most relevant "communication tools" of the Association, addressed to patients, friends, family members and anyone interested in knowing more about thoracic cancers. Through constant updating, the site provides everyone recent information, scientifically founded and controlled, accessible also for "non-sanitary" users. 


\section{Patients' support}

Primary WALCE's missions is to inform, educate and support lung cancer patients and their families offering them orientation and updated services. To answer this need, the Association has created many information booklets, specifically designed for patients, including relevant issues in thoracic oncology, such as cancer diagnosis, modern strategies of treatment, management of side effects, smoking cessation strategies and disease communication skills within the family (with a particular attention to children). The booklets, available in Italian and English, are currently distributed during national and international scientific events by oncologists, pulmonologists, radiotherapists, pharmacists, thoracic surgeons and family doctors throughout the national territory.

November was declared by the Global Lung Cancer Coalition "Month of Worldwide awareness of lung cancer", and on this occasion WALCE organizes numerous initiatives, including "How to feel better with a makeup". Since the first years of activity, in collaboration with oncology departments in Italy and other European cities, make-up laboratories are dedicated to patients undergoing cancer treatments, with the aim of sensitizing the population towards the pathology, give patients the opportunity to enhance their appearance and personality during such difficult period of their life, but also to favor those centers where programs like this do not exist on a regular basis.

Other activities offered to patients and caregivers during the path of illness are: "The mindfulness course", small group events carried out with the close collaboration of psycho-oncologists in order to teach patients techniques that aim not to focus on the disease, but to develop freedom to live beyond cancer and strengthen internal and external resources by acquiring greater self-confidence; courses of relaxation techniques, art therapy workshops and open-air pet therapy with trained dogs; cooking lessons for patients and family members, carried out with experienced chefs on natural cuisine, able to illustrate the natural properties of some foods and put them into practice in recipes for daily use.

\section{Patients' care}

Finally, in the recent years with the collaboration of some Pharma Companies and European researchers, has born EPROPA, a lung cancer patients support program designed and promoted by WALCE to offer equality in access to test, drugs and clinical trials across Europe. EPROPA main goal is to create a free-of-charge molecular screening platform for tumour characterization, in order to increase the detection of oncogenic drivers in lung cancer patients. The program will ensure teleconsulting to a National Reference Centre for patients with lung cancer to share clinical and pathological data. Tissue and plasma samples will be shipped to central laboratory for molecular screening and, on the basis of the results, to assess potential eligibility for therapeutic biomarker-driven clinical trials across Europe. The estimated turn-around time form samples shipment and tests results will be of 10 working days from sample reception. If the results will open the opportunity to enter in a dedicate clinical trial and the patient accepts to participate to this, EPROPA will help patients to reach the closest site where such study is available, covering for the cost of journey and staying of both patient and one caregiver during the experimental treatment. This extremely ambitious program well explains the heart of WALCE activity and its mission, in order to facilitate patient's approach to the disease and optimize cancer treatment.

\section{Conclusions}

Today, the best way to create a safe and large support network for cancer patients and achieve a multidisciplinary management of the disease, is the steady involvement of dedicated advocacies and patient associations together with professionals involved in this field. After more than 10 years from the first steps moved within the complex reality of patients' care and families' support, WALCE is now a well-established and recognised international association in the field of lung cancer: its dynamic activities, the careful care to any constituent of the society and its needs, the great energy of members and Association friends in every initiatives, make WALCE an example of patients advocacy largely committed to its mission and deeply integrated with other professionals involved in lung cancer care.

\section{Acknowledgments}

Funding: None.

\section{Footnote}

Provenance and Peer Review: This article was commissioned by the Guest Editor (Alfredo Tartarone) for the series "Improving outcomes in lung cancer through early diagnosis 
and smoking cessation" published in Fournal of Thoracic Disease. The article was sent for external peer review organized by the Guest Editor and the editorial office.

Conflicts of Interest: All authors have completed the ICMJE uniform disclosure form (available at http://dx.doi. org/10.21037/jtd.2020.03.76). The series "Improving Outcomes in Lung Cancer Through Early Diagnosis and Smoking Cessation" was commissioned by the editorial office without any funding or sponsorship. EC reports personal fees from MSD, personal fees from AstraZeneca, personal fees from Boehringer Ingelheim, outside the submitted work. SN reports personal fees from Eli Lilly, personal fees from MSD, personal fees from Roche, personal fees from BMS, personal fees from Takeda, personal fees from Pfizer, personal fees from Abbvie, personal fees from Celgene, personal fees from Astrazeneca personal fees from Boehringer Ingelheim, outside the submitted work. The authors have no other conflicts of interest to declare.

Ethical Statement: The authors are accountable for all aspects of the work in ensuring that questions related to the accuracy or integrity of any part of the work are appropriately investigated and resolved.

Open Access Statement: This is an Open Access article distributed in accordance with the Creative Commons Attribution-NonCommercial-NoDerivs 4.0 International License (CC BY-NC-ND 4.0), which permits the noncommercial replication and distribution of the article with the strict proviso that no changes or edits are made and the original work is properly cited (including links to both the formal publication through the relevant DOI and the license). See: https://creativecommons.org/licenses/by-nc-nd/4.0/.

Cite this article as: Capelletto E, Passiglia F, Ferraresi F, Vallone S, Novello S. Improving lung cancer outcomes through smoking cessation: the Women Against Lung Cancer in Europe (WALCE) experience. J Thorac Dis 2020;12(7):3877-3882. doi: $10.21037 /$ jtd. 2020.03 .76

\section{References}

1. Siegel RL, Miller KD, Jemal A. Cancer statistics, 2020. CA Cancer J Clin 2020;70:7-30.

2. Malvezzi M, Carioli G, Bertuccio P, et al. European cancer mortality predictions for the year 2019 with focus on breast cancer. Ann Oncol 2019;30:781-7.

3. Data available at: https://www.who.int/news-room/factsheets/detail/cancer

4. The Numbers of Cancer in Italy 2019. Available online: https://www.aiom.it/i-numeri-del-cancro-in-italia/, accessed on October, 16th, 2019.

5. GBD 2015 Risk Factors Collaborators. Global, regional, and national comparative risk assessment of 79 behavioural, environmental and occupational, and metabolic risks or clusters of risks, 1990-2015: a systematic analysis for the Global Burden of Disease Study 2015. Lancet 2016;388:1659-724.

6. Jha P, Ramasundarahettige C, Landsman V, et al. 21stcentury hazards of smoking and benefits of cessation in the United States. N Engl J Med 2013;368:341-50.

7. Jha P, Peto R. Global effects of smoking, of quitting, and of taxing tobacco. N Engl J Med 2014;370:60-8.

8. Data available at: https://www.who.int/nmh/events/ncd action_plan/en/

9. Data available at: https://www.who.int/tobacco/global_ report/2013/en/

10. Available online: http://www.womenagainstlungcancer.eu/

11. CDC. Centers for Disease Control and Prevention. Data available at: https://www.cdc.gov/tobacco/data_statistics/ fact_sheets/youth_data/tobacco_use/index.htm

12. Data available online: https://www.doxa.it/fumo-initalia-2017

13. Available online: http://www.womenagainstlungcancer.eu/ smetti-di-fumare/ 